\title{
English Reading Strategies and their Impact on Students' Performance in Reading Comprehension
}

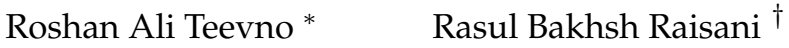

\begin{abstract}
In Pakistan, English is taught as a compulsory subject from grade one to graduate level. It has been given the status of official language and is considered a symbol of status. In all official correspondence English language is used and it opens up the avenues to have access to high-ranking civil service jobs. Research studies have revealed that students feel difficulty in reading, speaking and writing English at Secondary school level in Pakistan and they were found to be poor readers and receive lower grades in English language. Keeping in view the importance of learning English for students, this study was designed with the purposes to explore the strategies the students adopt for learning Reading English and to determine the effect of these adopted strategies on students' reading comprehension performance at secondary school level. Learning strategies are the basic techniques used for learning English in Pakistan. A survey was conducted to identify learning strategies used by the learners and their impact on reading comprehension performance of the learners. A sample comprising of 359 students was selected using stratified random sampling technique from amongst the Higher Secondary Schools and intermediate colleges located in district Naushahro Feroze Sindh Pakistan. Data for the study were collected through Questionnaire, interview protocol and reading comprehension test. The results indicated that students use variety of reading learning strategies including reading aloud, silent reading, summarizing the reading texts, outlining grammatical structures and patterns contained in the reading texts, answering simple questions, looking for the meaning of new vocabulary and translating English texts in their mother language. However, the use of these strategies by the students is not on a regular, systematic and need based. The analysis of the data revealed that learning strategies adopted by students for reading English were strongly correlated with their performance in reading comprehension. It was further found that students of urban area (mean score $=45.80$ ) performed significantly better than their peers in rural areas (mean score $=39.16$ ). However, while applying $t$-test of significance no significant difference in the performance of male and female learners (mean score: 42.07 \& 42.89) was detected. Additionally, students' performance in answering questions, summarizing, reading aloud, learning grammatical patterns, translating, looking for the meaning of vocabulary and learning spellings was satisfactory but their performance in analyzing, paraphrasing, prcising during reading was poor. The conclusion drawn is that students use different strategies for reading and that these adopted strategies have an effect on their reading comprehension. In terms of gender, there was no significant difference on use of strategies and impact on their reading performance, while students in urban area perform better than their peer in rural areas.
\end{abstract}

Keywords: Learning strategies, performance, gender difference, area difference.

\footnotetext{
${ }^{*}$ Research Scholar, Iqra University, Karachi Pakistan. E-mail: teevno@yahoo.com

${ }^{\dagger}$ Professor, Faculty of Education, Iqra University, Karachi, Pakistan.
} 


\section{Introduction}

English being international language has been playing an important role in bringing people in close contact worldwide and assumed a key role in social, economic and scientific development of the world. Khan (2007) believes that English has been playing a major role as an important source of communication globally. In Pakistan English received the status of official language and is taught as a compulsory subject from grade one to graduation.

Research findings have demonstrated that effective learning of English language depends upon the attitude, interest, attention and learning strategies of learners. Zare (2012) is of the opinion that "second language acquisition has repeatedly verified the significant role that learners can play in the process of language learning" (p. 162). Likewise, Ravindran (2016) suggests, "learners should adopt various learning approaches, methods and modes to make their English learning more effective". Lee (2010) adds that understanding of learners regarding learning strategies "can help students to learn more successfully and develop their learning autonomy" (p. 132).

Modern learning strategies and modes of learning are not the same that were practiced in remote past. The world has shrunk to a global village, where use of technology has revolutionized the world and has altogether changed the modes of learning of English as a second language (Ravindran, 2016). The learning strategies have changed and wide variety of language learning strategies including strategies for learning second language have been invented and adopted globally. Koondher (2015) believes that reading is continuous, interactive and dynamic process, where learners may build their new knowledge on the previous knowledge.

The literature clearly indicates that there is a distinct shift of focus from teaching methodologies to strategies of language learning (Kazi \& Iqbal, 2011). This shift has prompted (Liyanage, 2004) to assert that language-learning strategies occupy a central position in second language learning. In most of the schools of Pakistan, the methods adopted for English language teaching are the outdated grammar translation approach (Warsi, 2004), while language learning strategies are seldom taken into consideration (Kazi \& Iqbal, 2011).

The emphasis on second/foreign language learning now is more on how teachers and learners achieve their goals, and not on the teaching techniques (Kazi \& Iqbal, 2011). O'malley and Chamot (1990) describe language-learning strategy as particular thoughts or behaviors used by individuals for comprehending, learning and/ or retaining information. The use of strategies, "make learning easier, faster, more enjoyable, self-directed, effective, and transferable to new situations" cited in Oxford 2003, p. 8) provided they are in accordance with the task for which they are employed and are in harmony with the learning styles of individual learner cited in Kazi and Iqbal (2011).

Many Researchers have highlighted the importance and usefulness of use of strategies for learning a language. The use of language learning strategies not only give insight into the cognitive, metacognitive, social/ affective processes related to learning processes; but they can be taught to struggling language learners to assist them in language learning (Grenfell \& Harris, 1999) cited in Chamot (2005). The learner is not consciously aware 
of how to apply and use strategies, and needs to make them aware of and formally instructed by the teachers (Nyikos \& Oxford, 1993).

Students in Pakistan are unable to participate actively in reading strategies because of their weak knowledge of such strategies. Hence, they fail to gain maximum benefit of the reading activities carried out in the classroom and to use them meaningfully outside the classroom setting (Haq, 2016). Teachers generally do not use modern teaching strategies in reading of English rather they emphasize memorizing and to prepare students for public examinations (Khan, 2007). Students in Pakistan are unable to use cognitive and analytical capabilities to process the required information from longer passages by themselves, simply because they are not trained and prepared. This eventually results in poor performance in reading of English at higher secondary level (Mumtaz, 2006).

They exhibit lack of interest in using reading strategies, as their main aim is to pass examinations (Kasi, 2010). The main reading strategies of Pakistani students include summarizing the text, reading for information, answering comprehension questions, and reading aloud (Gulzar \& Qadir, 2010). Ahmed (1979) argues that teachers at higher secondary level in Pakistan have not been able to adopt reading strategies according to the needs and interest of the students. Shahzada (2012) believes that although students in Pakistan use different reading strategies but overall performance of students in reading of English is not up to the mark.

In short, teaching of English as a second language in general, and learning of reading in particular, encounters enormous challenges at higher secondary school level in Pakistan. Learning reading English demands that it should be studied more systematically using a scientific approach of inquiry to find out reading learning strategies adopted by students in reading English and further to ascertain the impact of these adopted reading strategies on students' reading comprehension at higher secondary level. Therefore, this study was conceptualized and designed with the main purpose to explore the reading strategies used by students for reading English and to determine the impact (if any) of these adopted strategies on their reading performance.

\section{Research Questions}

1. What specific learning strategies do students use in learning reading English at higher secondary school level?

2. To what extent do the learning strategies affect the performance of students in reading comprehension?

3. What are the perceptions of students regarding their learning strategies in reading of English at higher secondary school level?

\section{Null Hypotheses}

$H o_{1}$ : There is no significant impact of students' adopted learning strategies on their reading comprehension performance at higher secondary level. 
$\mathrm{Ho}_{2}$ : There is no significant difference between male and female students' performance in reading comprehension of English.

$\mathrm{Ho}_{3}$ : There is no significant difference between rural and urban students' performance in reading comprehension of English.

\section{Literature Review}

Reading strategies refer to one kind of monitoring system that involves readers' selfreflection, awareness of interaction with text and relationship of reading strategies and text comprehension (Singhal, 2001) and the aim of reading strategies is to understand the meaning of the given text (Thompson, 1988). According to Suwantharathip (2015), reading strategies is collaborative approach in reading process and includes the use of cognitive and meta-cognitive strategies. Good teaching and learning strategies in reading serve multiple purposes including improving other skills of the language (Alderson, 2000) including writing and speaking skills (Suwantharathip, 2015).

Teaching and learning strategies always play an important role in the development of Second and/or foreign language learning skills including reading skill. Mehrdad, Ahghar, and Ahghar (2012) reported that regular use of teaching reading strategies can make learners more confident and their reading comprehension can considerably improve in second language, the language that is not the first or mother language of the reader (Duke \& Pearson, 2012). Naeini (2015) substantiated these assertions by reporting that students use more meta-cognitive strategies as compared to cognitive strategies and those who used reading strategies performed better in reading tests than those who did not use strategies.

The use of reading strategies and their impact on students reading comprehension performance has been the focus of attention of many researchers. Numerous studies have examined the possible relationship between use of reading strategies and students' reading performance. Zhang and Seepho (2013) in a study on a sample of Chinese foreign language learner (EFL) University students investigated the meta-cognitive strategies of English and its relationship with students' academic reading comprehension found that the performance of the students in reading comprehension of English and meta-cognitive strategies were closely related. The results indicated that there was a significant positive correlation between the use of meta-cognitive strategy and English reading comprehension.

Khezrlou (2012) reported a significant relationship between reading strategies and performance of the students. The use of strategies and their impact however, was found to be different for different age groups and their level of education. Phakiti (2006) in a study determining the impact of various reading strategies found that planning strategies did not have any direct impact on reading strategies of the learners, whereas, the monitoring strategies had direct impact on memory based strategies of the learners. Similarly, Zare and Othman (2013) examining the relationship between the use of reading strategies and reading comprehension of Malaysian English as second language (ESL) learners found 
that the use of reading strategies had a positive relationship with reading comprehension achievement. The results further revealed a significant difference between male and female learners in the use of reading strategies. Zare (2012) reported a strong positive correlation between use of reading strategies reading and comprehension achievement but the results also showed no significant difference in the use of reading strategies between male and female language learners.

Karami and Hashemian (2012) in a study on sample of Iranian Elementary Female Second language learners (L2) learners' examined the effect of learners' meta - cognitive learning strategy knowledge on their reading comprehension in three different stages of reading (Pre-reading, while - reading and post-reading). They found a significant relationship between reading comprehension and use of meta-cognitive strategy by young group of respondents (15- 20 years of age). Tavakoli (2014) reported a strong positive correlation between reported meta-cognitive awareness of reading strategies, and reading comprehension performance of Iranian EFL learners. The results also revealed that their levels of English proficiency significantly influenced students' knowledge of meta-cognitive reading strategies. Tavakoli (2014) conducted an experimental study determining the effect of meta-cognitive strategy instruction on English as a foreign Language (EFL) learners' reading comprehension performance and metacognitive awareness found that two experimental groups who received instruction on meta-cognitive strategies (planning and self-monitoring) outperformed the control group on the reading comprehension test.

Chaury (2015) in a meta-analysis investigated the effects of strategy instruction on reading comprehension in English as a foreign language and the effect of moderating variables that may have influenced the outcome of the strategy instruction. The analysis revealed an overall effect indicating that, on average, EFL students who received strategy instruction outperformed their counterparts who did not receive strategy instruction. Molla (2015) in an attempt to find out possible relationships between reading strategy use and reading comprehension reported no significant relationship (positive or negative) between use of reading strategies and reading comprehension.

The reviews above clearly indicate that students use different reading strategies for reading comprehension and that different learning reading strategies of second language had significant impact on reading performance of the learners. The impact was different for different age groups and their level of education and type of strategy used. The literature also revealed that in Pakistan, the focus of studies was on exploring the type of strategies used by students for reading English. However, no study for ascertaining the impact of use of reading strategies on reading performance was conducted in Pakistan. Thus, a need was felt to fill this gap.

Based on the review of literature, the conceptual framework that emerged was that use of different categories of strategies such as cognitive, meta-cognitive and/or affective/social strategies for reading English as a second language could have varying effects on students' reading performance. It was further postulated that strategy use may have varying effect on students reading comprehension performance on the basis of their gender and location of the institutions.

The conceptual framework in figure 1 below also assumes that each strategy alone or in combination influences the reading comprehension of students. It also suggests that 
a particular strategy may have a greater impact as compared to the other strategies but overall thesis is that the strategies adopted by students may influence students' reading performance. The framework also shows as indicated by two-tailed arrows that use of reading strategies may vary in relation to Rice's classification (2009) of pre-reading, while-reading and post-reading stages.

Figure 1

Conceptual Framework of the Study

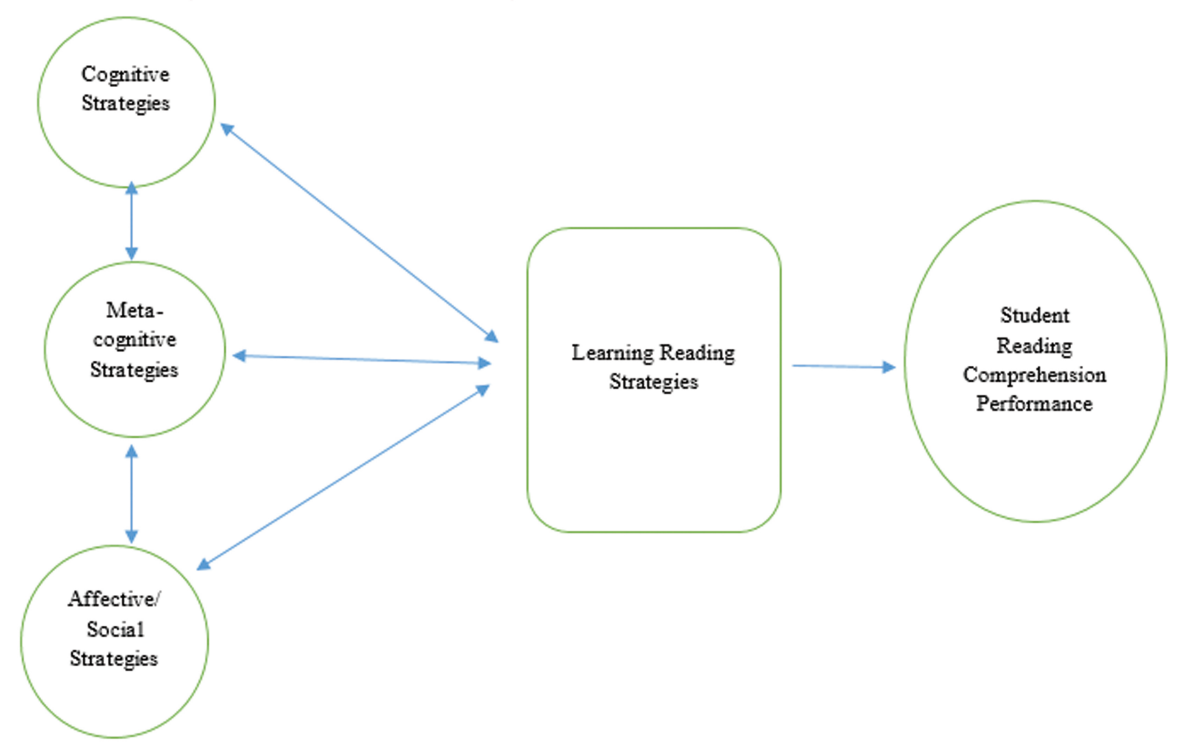

\section{Methodology}

\section{Method and Instruments}

Concurrent and Sequential (quantitative + qualitative) explanatory Mix Method design was employed for the study. A mixed methods research is a procedure for collecting, analyzing, and "mixing" both quantitative and qualitative research and methods in a single study to understand a research problem (Creswell, 2008). Using Cross-sectional survey, the quantitative data was collected through researcher developed Likert type closeended questionnaire for exploring the reading strategies adopted by students in English language learning and reading comprehension test for measuring students' performance in reading comprehension. While qualitative data was gathered through semi-structured interview protocol. Before administering the Questionnaire to the original sample, it was piloted on a small sample of students for determining its suitability and reliability. The 
necessary modifications and changes were incorporated in light of the suggestions of pilot testing. The reliability of the instrument (Questionnaire) was computed using Cronbach alpha estimates which was. 88 above the acceptable level of reliability for any research instrument. The validity check was done with expert opinion and based on their expert views, necessary changes and modifications were made in the instrument.

\section{Sample and Sampling Procedure}

The population for the study comprised of all 12th grade students in higher secondary Schools and colleges in the year 2015-16. The sample for the study was drawn from the population using stratified random sampling technique. The strata for the study included the gender of the respondents and the location of the institutions from which the sample was selected. The selected sample consisted of 359 (230 male and 129 female) students of grade 12 from higher secondary schools (male/female) and degree colleges of district Naushahro Feroze Sindh Pakistan.

\section{Data Analysis/ Results}

\section{Results of Quantitative Data}

The data in the Table 1 indicates that almost half of the respondents showed interest in reading English text (item \# 1) and placed emphasis on reading skills than other language learning skills (item \# 13). The respondents sought the guidance of their teachers in case they faced any difficulty in reading (item \# 5) and understanding of new vocabulary but at the same time they failed to share their ideas with peers after doing reading. Majority of the respondents indicated that they used different reading strategies and/or techniques in reading English texts including reading aloud (item \# 2), translating English text in their mother tongue (item \# 8) answering comprehension question during reading aloud (item \# 10) and answering questions relating to specific information during reading aloud (item \# 11); summarizing English text (item \# 22) looking for specific information in the text (item \# 23).

The respondents identified different methods for improving reading capability including use of dictionary (item \# 17), reading English grammar books for learning new grammar structures and patterns (item \# 18 \& 26). But asked to indicate whether they read English stories (item \# 27) English newspapers (item \# 44) and/or use internet (item \# 28), only a very small percentage of respondents expressed their agreement with the statements indicating that they do not use internet or read newspapers and/or any story books. It could be that they do not have access to such facilities.

Majority of students expressed disagreement with the statements that they use their background knowledge for reading (item \# 19) understanding the inherent message in the written text (item \# 15), doing fast reading of English text for extracting the gist of the text (item \# 20), doing silent reading (item \# 140, reading English text fluently (item \# 6), assigning title to untitled text (item \# 21), guessing meaning of new vocabulary and 


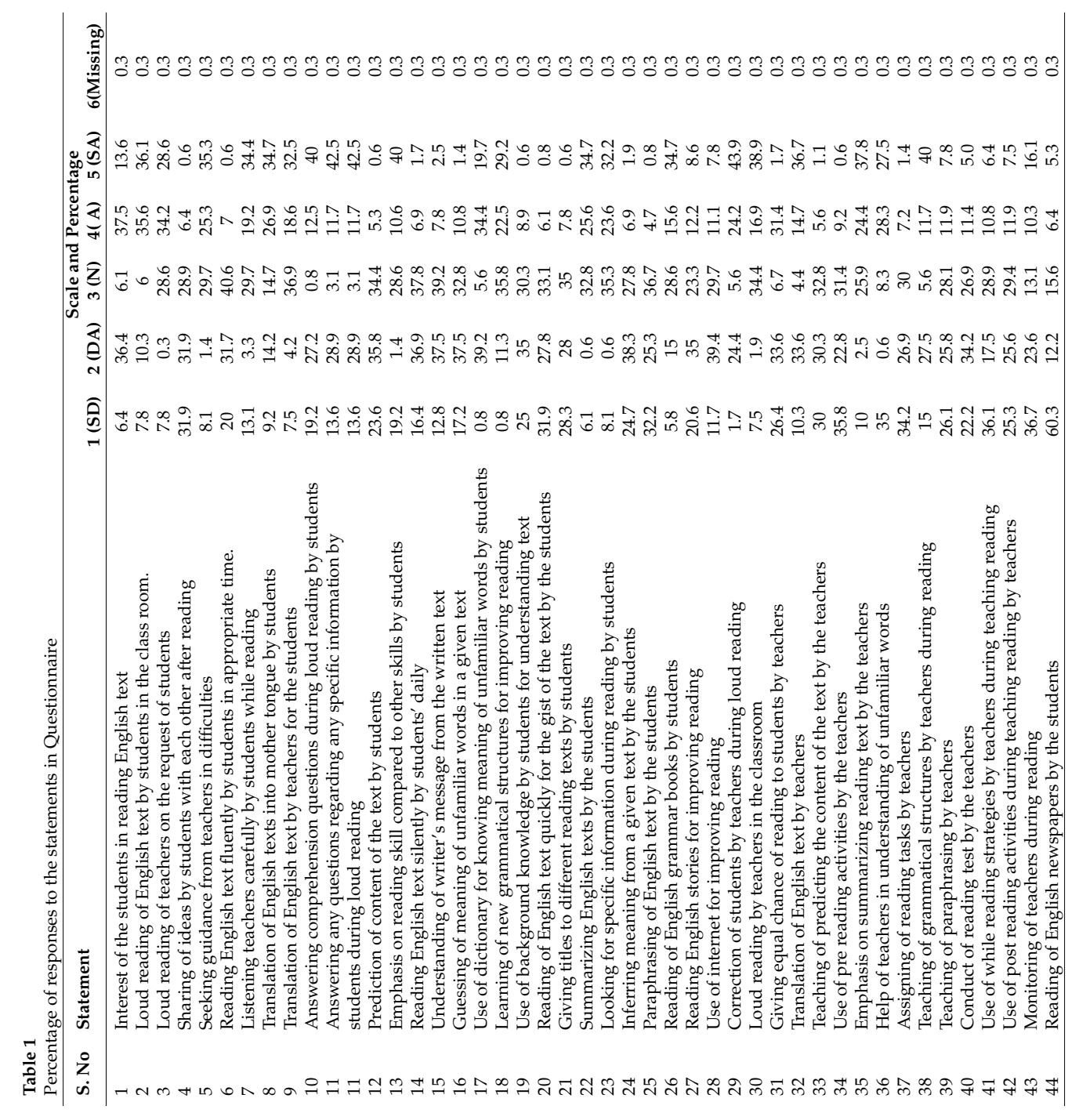


unfamiliar words (item \# 16), paraphrasing text (item \# 25), inferring meaning (item \# 24) and predicting content of a given text (item \# 12).

The students were of the opinion that on their request their teachers do the loud reading for them (item \# 3) and translate English text in mother language (item \# 32), emphasizing to summarize the text (item \# 35), teach grammatical structures and patterns during reading (item \# 38). But at the same time they were in disagreement with the statements that their teachers assign reading tasks (item \# 37), teach them to do paraphrasing (item \# 39), predicting the content of a text (item \# 33) and using pre-reading activities (item \# 34), while reading activities (item \# 41) and post reading activities. Majority of the respondents was of the view that their teachers fail to provide equal chance of reading to all students (item \# 31), monitor students reading (item \# 43) and conduct tests to gauge reading capabilities of students (item \# 40).

\section{Results of Hypotheses Testing}

\section{$H o_{1}$ : There is no significant impact of learning strategies of students on their reading comprehension performance at higher secondary level.}

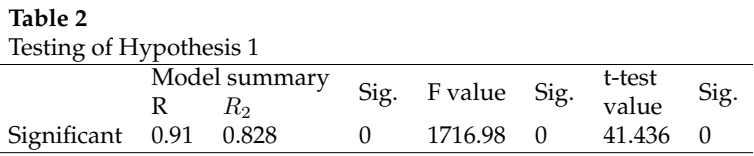

\section{Analysis}

Table 2 reveals that learners' strategies have significant impact on their English reading comprehension performance $(p=000, R=.910)$. Learning strategies is a very strong predictor of the performance of the students since the learning strategies variable is carrying $\mathrm{R}$ value $=.910$, has accounted for $\mathrm{R} 2=82.8 \%$ of variance in the achievement of learners. Moreover, significant $F$ value indicates that regression model is fit and can significantly predict the performance of the students. Similarly, significant $t$ value indicates that changes in the value of learners' performance are significant due to changes in the values of predictor variable. Hence, null hypothesis is rejected, concluding that proper adoption of learning strategies will lead towards significant improvement in students' performance in reading of English. 


\section{$\mathrm{Ho}_{2}$ : There is no significant difference between male and female students' performance} in reading comprehension of English.

Table 3

Testing Hypothesis 2

\begin{tabular}{llcccccc}
\hline & & \multicolumn{5}{c}{ t-test for Equality of Means } \\
\hline & & $\mathrm{T}$ & $\mathrm{df}$. & Sig. (2-tailed) & Mean Diff & Std. Error Diff \\
$\begin{array}{l}\text { Performance of students } \\
\text { in reading comprehension }\end{array}$ & Equal variances assumed & 1.161 & 357 & 0.247 & 0.30226 & 0.26045 \\
& & & & & & & \\
& Equal variances not assumed & 1.169 & 270.847 & 0.244 & 0.30226 & 0.25861 \\
\hline
\end{tabular}

\section{Analysis}

The data in the table 3 indicates that Sig (2) tailed value is greater than .05 , therefore, it is concluded that there is no significant difference between male and female students' performance in reading comprehension of English. Thus, the null hypothesis that stated a no significant difference between male and female students' performance in reading comprehension is upheld.

\section{$\mathrm{Ho}_{3}$ : There is no significant difference between urban and rural students' performance} in reading comprehension of English.

Table 4

Testing of Hypothesis 3

\begin{tabular}{|c|c|c|c|c|c|c|}
\hline \multirow{3}{*}{$\begin{array}{l}\text { Performance of students } \\
\text { in reading comprehension }\end{array}$} & \multirow[b]{3}{*}{ Equal variances assumed } & \multicolumn{5}{|c|}{ t-test for Equality of Means } \\
\hline & & $\mathrm{T}$ & Df. & Sig. (2-tailed) & Mean Diff & Std. Error Diff \\
\hline & & -2.116 & 357 & 0.035 & -0.52818 & 0.24966 \\
\hline & Equal variances not assumed & -2.128 & 353.965 & 0.034 & -0.52818 & 0.24825 \\
\hline
\end{tabular}

\section{Analysis}

The data in the table 4 indicates that Sig (2) tailed value is less than .05, therefore, it is concluded that there is significant difference between urban and rural students' achievement in reading comprehension of English at higher secondary level. Thus, the null hypothesis that stated a no significant difference between male and female students' performance in reading comprehension is rejected.

Table 5

\begin{tabular}{lccc}
\multicolumn{4}{l}{ Comprehension test mean } \\
\hline Urban area & Rural area & Male & Female \\
\hline 45.8 & 39.16 & 42.07 & 42.89 \\
\hline
\end{tabular}

\section{Analysis}

The above table 5 shows that mean score of urban area students was 45.8 , a rural area student was 39.16, male student was 42.07 and female student was 42.89 respectively. The 
data indicate that Urban students' performance was better as compared to the students in rural areas, while the data did indicate no significant difference in the performance of male and female students in reading comprehension.

\section{Results of Qualitative Data}

The qualitative data revealed that students read English texts regularly and translate the same in their mother languages for comprehension. Textbook is most commonly used source for reading and they prefer to read aloud and ask their teachers to read for them and seek their help in translating the passage, correcting their pronunciation and meaning of new words and vocabulary. The main learning strategies as reported by students included summarizing the text, answering the questions based on specific information, translating the text in their mother language, reading grammar books, finding meaning of different new words, matching columns, filling gaps, underling different ideas and grammatical structures and patterns. The students also expressed difficulties in precising longer texts, paraphrasing and skimming to extract the gist of the text and to assign a suitable tittle to a reading passage/text and expressing and explaining them in English language. They also expressed their inability to infer meaning from the text, predicting the content of the text and to using background knowledge and analyzing the text they read in English.

\section{Discussion}

The findings of the study reveal that students use a number of strategies; however, the use of these strategies is not on a regular basis or a specific purpose in mind. Most of the strategies adopted were simple in nature such as summarizing a text, reading aloud and to translating texts in their mother languages. These findings lend support to the findings of Gulzar and Qadir (2010) who found that main reading strategies of Pakistani students include summarizing the text, reading for information, answering comprehension questions, and reading aloud. The students perform tasks like filling gaps, underling, column matching, translating text, summarizing, finding meaning of new vocabulary. The main source of their readings is textbooks or at the most use of Grammar books. Therefore, their reading was not rich enough to help them to accumulate a good stock of vocabulary, and to use the strategies that could help them in prcising texts, predicting the content of the text and paraphrasing and skimming strategies to become independent readers. This was because there was no strategy teaching by their teachers and they were dependent on teachers and sought their help in in translating the passage, correcting their pronunciation and meaning of new words and vocabulary. These findings lend support to the findings of (Qanwal \& Karim, 2014), who found that students are not taught the required reading strategies to become independent learners, the teaching reading strategies adopted by teachers were not in line with needs and interests of the students (Ahmed, 1979). Khan (2007) also reported somewhat similar results that the task given to the students are not creative and to develop the rational skills of students. The findings also substantiated 
the findings of Shahzada (2012) that although students in Pakistan use different reading strategies but overall performance of students in reading of English is not up to the mark.

The findings of the study that indicated a strong relationship between reading strategies adopted by students and their performance in reading comprehension is consistent with the findings of most of the study that have reported similar findings. The findings of this study corroborate the findings of Khezrlou (2012) reported a significant relationship between reading strategies and performance of the students; Zare (2012) and Zare and Othman (2013) reported a strong positive relationship between students' use of reading strategies and reading comprehension achievement. The findings of the study were in harmony with the findings of (Karami \& Hashemian, 2012). They examining the effect of learners' meta- cognitive learning strategy knowledge on their reading comprehension at three different stages of reading (Pre-reading, while- reading and post-reading) found a significant relationship between reading comprehension and use of meta-cognitive strategy by young group of respondents. Tavakoli (2014) reported a strong positive correlation between reported meta-cognitive awareness of reading strategies, and reading comprehension performance of Iranian EFL learners were substantiated by the findings of the study. The findings of this study are however in contradiction to the findings by Molla (2015) found no significant relationship (positive or negative) between use of reading strategies and reading comprehension of students.

The study indicated interesting findings, on the one hand, a significant difference was found between performance of rural and urban students in reading comprehension where the urban students demonstrated better performance than their peers in rural areas were. This finding could be attributed to availability of better human and other reading material/ resources in urban areas. While, comparing the performance of male and female students, the results revealed no significant difference between performances of these two groups of students. This finding is similar to the findings reported by Zare and Othman (2013) who found no significant difference in the use of reading strategies between male and female language learners.

\section{Implications}

The findings have clear implications for teachers, curriculum developers and designers that use of strategies by students has strong and positive correlation with students' performance in reading comprehension. The findings have clearly highlighted the positive impact and benefit of reading strategies. This makes it imperative for teachers to focus on teaching reading strategies and motivate students to use strategies for improving their performance in reading English. Similarly, curriculum developers and designers should include contents and learning experiences in curriculum that could compel and induce teachers and curriculum implementers to ensure maximum use of reading strategies for improving students' performance. However when performance of male and students were compared, the data indicated no significant difference in their performance. This indicates that use of reading strategies has no significant effect on students' reading performance on the basis of their gender. It implies that teachers and curriculum implementers should not worry to specify any specific reading strategies on the basis of their 
gender. The finding that urban students' performance in reading English was better than the performance of rural students should be a concern of teachers and administrators. It indicates that urban schools and colleges are better equipped with human, material and other reading resources that have helped them to show improved performance. It implies that resources should be equally distributed and provided in urban and rural areas so that students in rural areas improve their reading comprehension performance.

\section{Conclusion}

The major conclusion that could be drawn from this study is that that there is significant positive relationship between use of strategies adopted by students and their performance in reading comprehension. The students used a number of strategies for reading, the used strategies however, were confined to answering questions, summarizing the text, reading aloud, learning grammatical patterns, and translating text into mother language, looking for the meaning of vocabulary and learning spellings. However, students had difficulty in prcising longer texts, paraphrasing and skimming to extract the gist of the text and to assign a suitable tittle to a reading passage/text and expressing and explaining them in English language. This requires that students should be taught reading strategies that could develop their knowledge and skills in the areas they were deficient. A significant difference in reading comprehension of students of urban and rural areas. was revealed. The urban students exhibited better performance as compared to the students in rural areas, while no significant difference was found in reading performance of male and female students indicating that influence of use of reading strategies is the same for both the genders.

\section{Recommendations}

Based on the findings of the study, it is suggested that teachers should focus more on strategy teaching using student-centered teaching methods and provide students opportunities to put in practice different cognitive, meta-cognitive and social strategies so that they should improve their performance in areas where found to be deficient. The administrators should make sure that necessary resources are made available to all segments of students in rural and urban areas. This study was confined to one district of Sindh province; it should be expanded to include students of other districts to determine if the findings are tenable. This study was also limited to the perceptions of students only, the future studies should include other stake holders (Teachers/Principals/Head teachers) in exploring the reading strategies adopted by students and their impact on their performance in reading comprehension. 


\section{References}

Ahmed, Z. (1979). Evaluation of the effectiveness of an improvement method of teaching english to 9th grade student. Unpublished) Ph. D. thesis, Institute of Educational and Research, University of Punjab, Lahore Pakistan, 143-156.

Alderson, J. C. (2000). Assessing reading. Cambridge: Cambridge University Press.

Chamot, A. U. (2005). Language learning strategy instruction: Current issues and research. Annual Review of Applied Linguistics, 25, 112-130.

Chaury, P. (2015). The effects of strategy instruction on reading comprehension in english as a foreign language. Concordia working papers in Applied Linguistics.

Creswell, J. W. (2008). Educational research: planning, conducting and evaluating quantitative and qualitative research. Columbus, Ohio: Pearson education Ltd.

Duke, N., \& Pearson, P. (2012). Effective practices for developing reading comprehension in AE Farstup, \& SJ Samuels (Eds.), What research has to say about reading instruction? DE: International Reading Association.

Grenfell, M., \& Harris, V. (1999). Modern languages and learning strategies: In theory and practice. London: Routledge.

Gulzar, M. A., \& Qadir, S. A. (2010). Issues of language (s) choice and use: A Pakistani perspective. Pakistan Journal of Social Sciences, 30(2), 413-424.

Haq, A. (2016). Analysis of English language: Needs for higher education in Bangladesh. Institute of Bangladesh studies, Rajshahi University, Rajshahi.

Karami, S., \& Hashemian, M. (2012). The relationship between (meta) cognitive strategies and reading comprehension in Iranian female L2 learners. International Journal of English Linguistics, 2(4), 58-64.

Kasi, F. (2010). Collaborative action research: An alternative model for efl teacher professional development in pakistan. Asian EFL Journal, 12(3), 98-117.

Kazi, A. S., \& Iqbal, H. M. (2011). Use of language learning strategies by students at higher secondary level in Pakistan. International Journal of Social Sciences E Education, 1(4), $555-574$.

Khan, H. A. (2007). A needs analysis of Pakistani state boarding schools secondary level students for adoption of communicative language teaching (Unpublished doctoral dissertation). MA Diss. School of Arts \& Education of Middlesex University, London.

Khezrlou, S. (2012). The relationship between cognitive and metacognitive strategies, age, and level of education. The Reading Matrix, 12(1), 50-61.

Koondher, M. A. (2015). Developing reading comprehension through metacognitive strategies: A review of previous studies. English Language Teaching, 8(8), 181-186.

Lee, C. K. (2010). An overview of language learning strategies. Annual Review of Education, Communication \& Language Sciences, 7(1), 132-152.

Liyanage, I. J. B. (2004). An exploration of language learning strategies and learner variables of Sri Lankan learners of English as a second language with special reference to their personality types (Unpublished doctoral dissertation). Unpublished doctoral thesis. Griffith University, Queensland, Australia.

Mehrdad, A. G., Ahghar, M. R., \& Ahghar, M. (2012). The effect of teaching cognitive and metacognitive strategies on EFL students' reading comprehension across profi- 
ciency levels. Procedia-Social and Behavioral Sciences, 46, 3757-3763.

Molla, B. (2015). The relationship between reading strategy use and reading comprehension among Ethiopian EFL learners. The Reading Matrix, 15(3), 34-41.

Mumtaz, K. (2006). Methods of teaching English. Lahore: Ch Gullam Rasool \& Sons.

Naeini, M. B. (2015). Examining and dealing with the issue of reading strategy use by Iranian EFL learners. The Reading Matrix: An International Online Journal, 15(2), 182195.

Nyikos, M., \& Oxford, R. (1993). A factor analytic study of language-learning strategy use: Interpretations from information-processing theory and social psychology. The Modern Language Journal, 77(1), 11-22.

O'malley, J. M., \& Chamot, A. U. (1990). Learning strategies in second language acquisition. London: Cambridge University Press.

Phakiti, A. (2006). Modeling cognitive and metacognitive strategies and their relationships to EFL reading test performance. Melbourne Papers in Language Testing, 1(1), 53-96.

Qanwal, S., \& Karim, S. (2014). Identifying correlation between reading strategies instruction and L2 text comprehension. Journal of Language Teaching $\mathcal{E}$ Research, 5(5), 1019-1032.

Ravindran, S. (2016). Modes of learning English as a second language and the role of motivation: A case study on the second year students of the Faculty of Arts, University of Jaffna. ELT Voices- International Journal for Teachers of English, 6(6), 5-15.

Shahzada, G. (2012). Views of the teachers regarding the students' poor pronunciation in English language. Journal of Educational and Social Research, 2(1), 309-316.

Singhal, M. (2001). Reading proficiency, reading strategies, metacognitive awareness and L2 readers. The Reading Matrix, 1(1), 1-9.

Suwantharathip, O. (2015). Implementing reading strategies based on collaborative learning approach in an English class. Reading Matrix: An International Online Journal, 15(1), 91-101.

Tavakoli, H. (2014). The effectiveness of metacognitive strategy awareness in reading comprehension: The case of Iranian university EFL students. Reading Matrix, 14(2), 314-336.

Thompson, I. (1988). Reading research and its curricular implications. Slavic and East European Journal, 32(4), 617-642.

Warsi, J. (2004). Conditions under which English is taught in Pakistan: An applied linguistic perspective. Sarid Journal, 1(1), 1-9.

Zare, P. (2012). Language learning strategies among EFL/ESL learners: A review of literature. International Journal of Humanities and Social Science, 2(5), 162-169.

Zare, P., \& Othman, M. (2013). The relationship between reading comprehension and reading strategy use among Malaysian ESL learners. International Journal of Humanities and Social Science, 3(13), 187-193.

Zhang, L., \& Seepho, S. (2013). Metacognitive strategy use and academic reading achievement: Insights from a Chinese context. Electronic Journal of Foreign Language Teaching, 10(1), 54-69. 